\title{
Reductive Carbonylation of Nitroarenes Using a Heterogenized Phen-Pd Catalyst
}

Sudakar Padmanaban, ${ }^{\mathrm{a} \ddagger}$ Vinothkumar Ganesan, ${ }^{\mathrm{b} \ddagger}$ Sungho Yoon,${ }^{\mathrm{b} *}$ and Yunho Lee ${ }^{\mathrm{a} *}$

aDepartment of Chemistry, Seoul National University, Seoul 08826, Republic of Korea.

E-mail: yunhochem@snu.ac.kr

${ }^{b}$ Department of Chemistry, Chung-Ang University, Seoul 06974, Republic of Korea.

E-mail: sunghoyoon@cau.ac.kr

\section{Characterization data}

Table S1. Elemental analysis of $\mathbf{2}$ and $\mathbf{3 .}$

\begin{tabular}{|c|c|c|c|c|}
\hline Sample & $\mathrm{C}$ & $\mathrm{N}$ & $\mathrm{H}$ & $\mathrm{C} / \mathrm{N}$ \\
\hline Phen-POP & 70.26 & 5.31 & 4.30 & 13.23 \\
\hline Bathophenanthroline & 86.68 & 8.46 & 4.93 & 10.24 \\
\hline
\end{tabular}

Table S2. BET analysis of $\mathbf{2}, \mathbf{3}$ and ICP-OES data.

\begin{tabular}{|c|c|c|c|}
\hline Material & SBET $\left(\mathrm{m}^{2} / \mathrm{g}\right)$ & $\begin{array}{c}\text { Pore volume } \\
\left(\mathrm{cm}^{3} / \mathrm{g}\right)\end{array}$ & $\begin{array}{c}\text { Pd content by } \\
\text { ICP-OES (wt\%) }\end{array}$ \\
\hline phen-POP (2) & 525 & 0.25 & -- \\
\hline Pd@phen-POP (3) & 450 & 0.23 & 1.97 \\
\hline
\end{tabular}


Figure S1. SEM images of phen-POP (2) with different magnification (a) and (b).
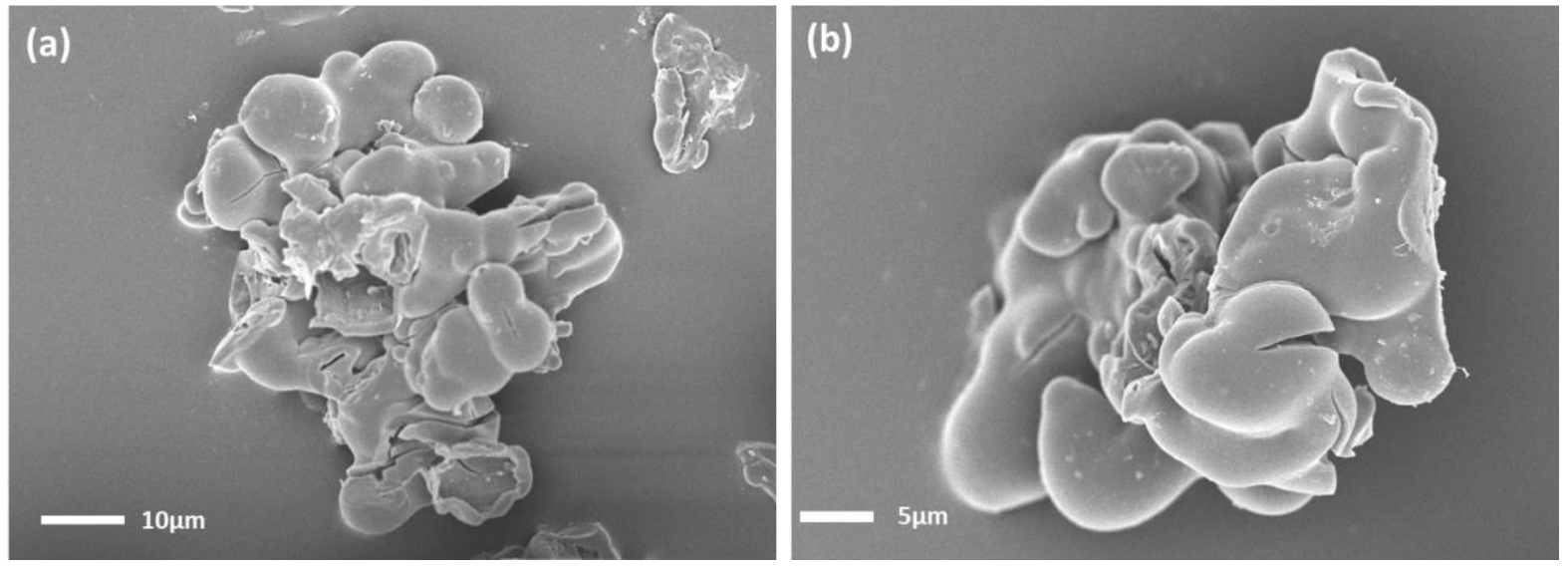

Figure S2. SEM-EDX spectrum of Pd@phen-POP (3) showing the coexistence of Pd, C, N, B, and $\mathrm{F}$ atoms.

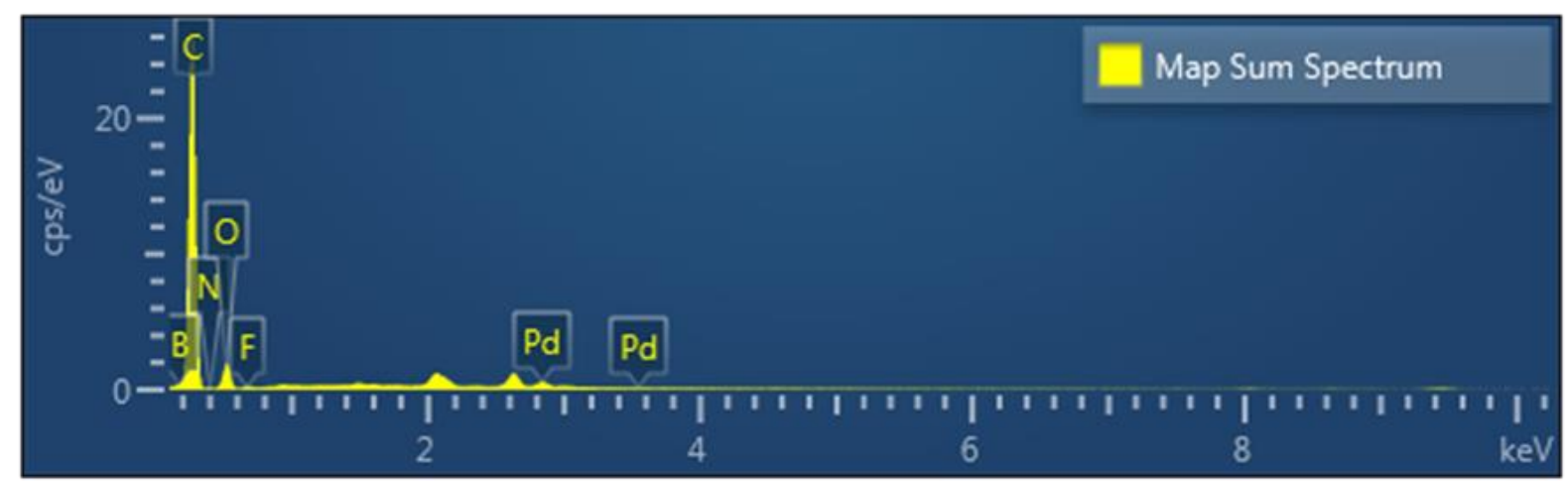


Figure S3. Powder X-ray diffraction (PXRD) spectra of phen-POP (2) (black line) and Pd@phen-POP (3) (red line).

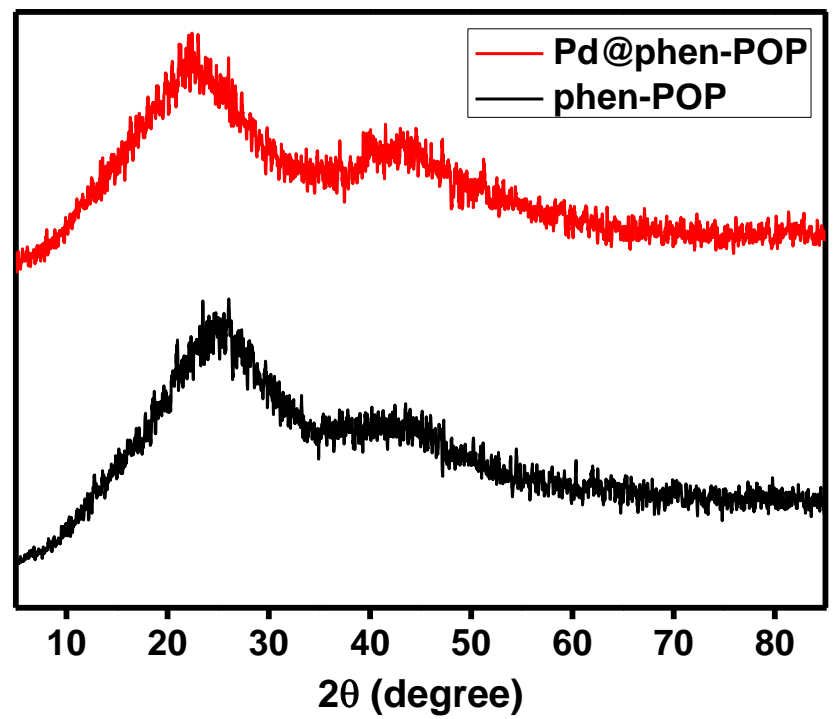

Figure S4. An XPS survey spectrum of phen-POP (2).

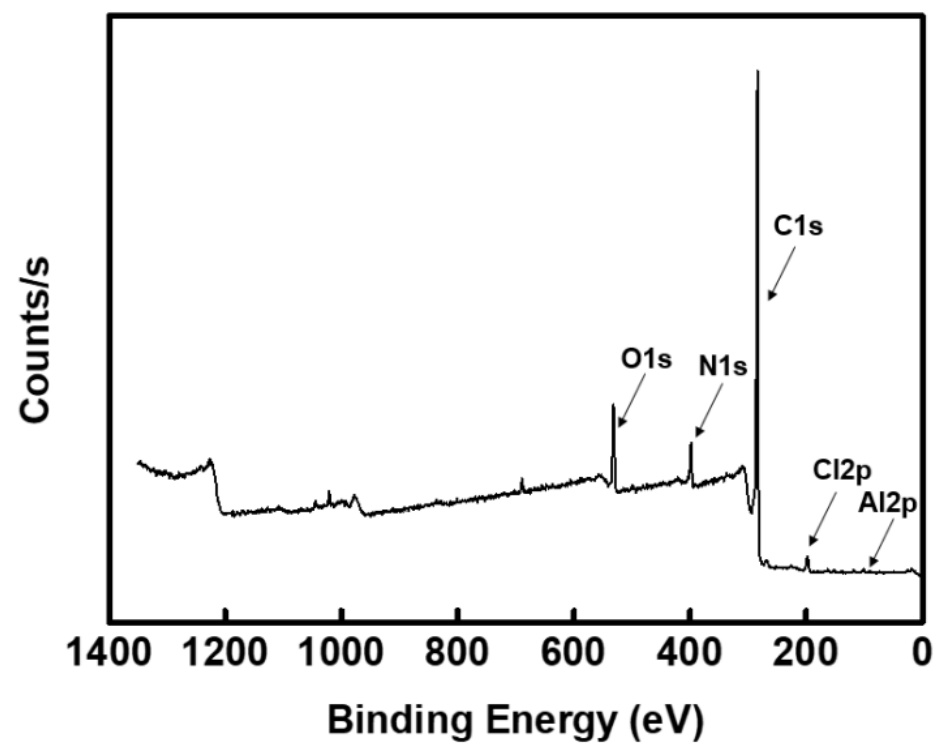


Figure S5. TGA data of phen-POP (2).

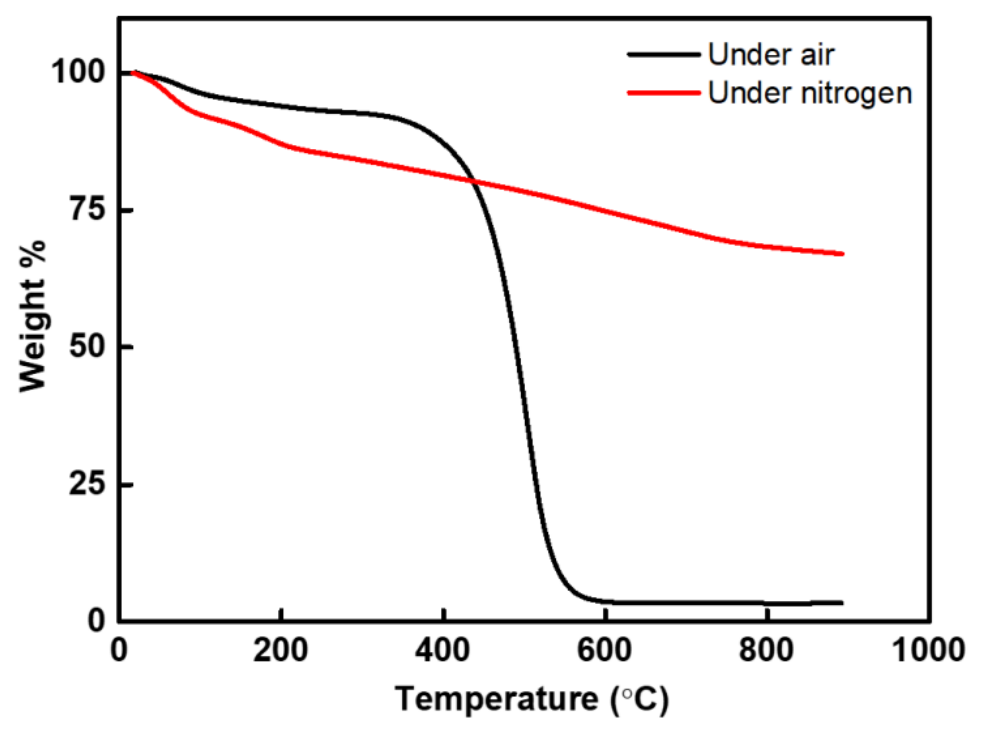

Figure S6. (a) The N1s core region of the N atom in the XPS spectrum of 3. Black: experimental data, red: simulated data, green: ligated $\mathrm{N} 1 s$ and unligated $\mathrm{N} 1 s$. (b) The $\mathrm{N} 1 s$ core region of the $\mathrm{N}$ atom in the XPS spectrum of 1. Black: experimental data, red: simulated data, green: ligated $\mathrm{N} 1 s$.
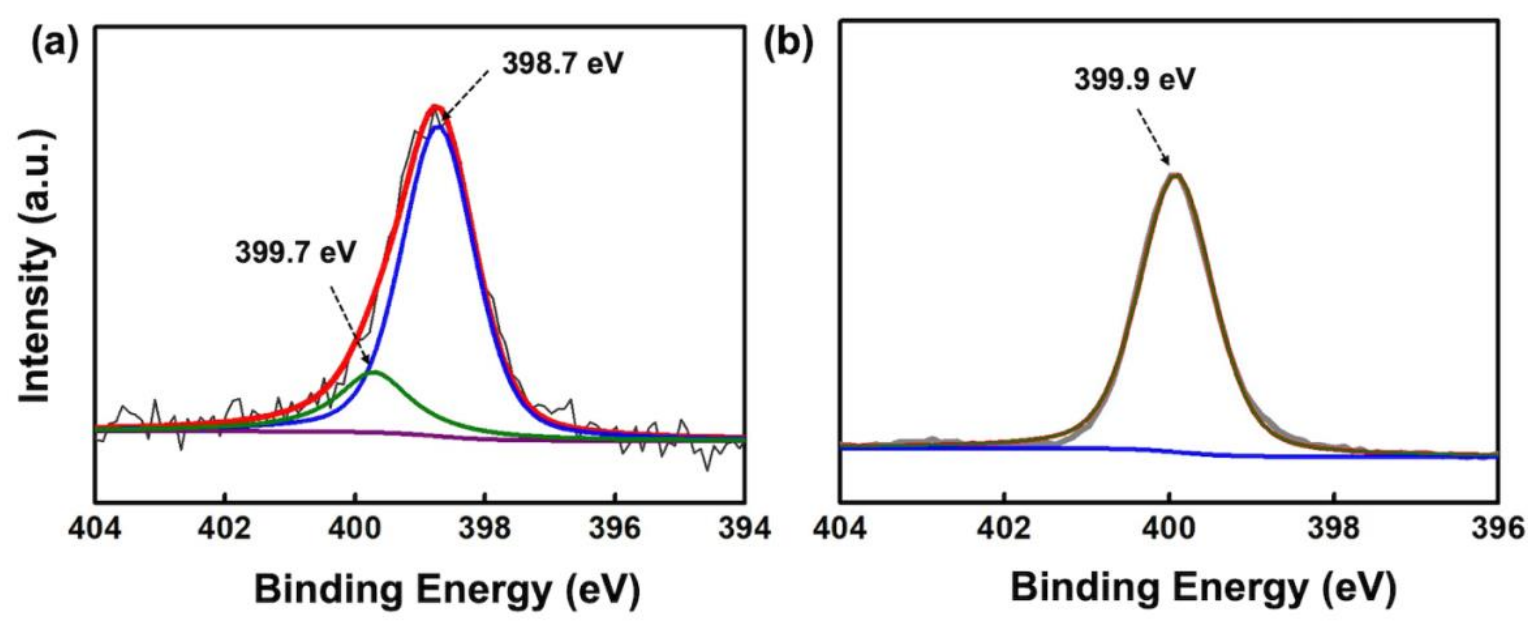
Figure S7. A Hot filtration test.

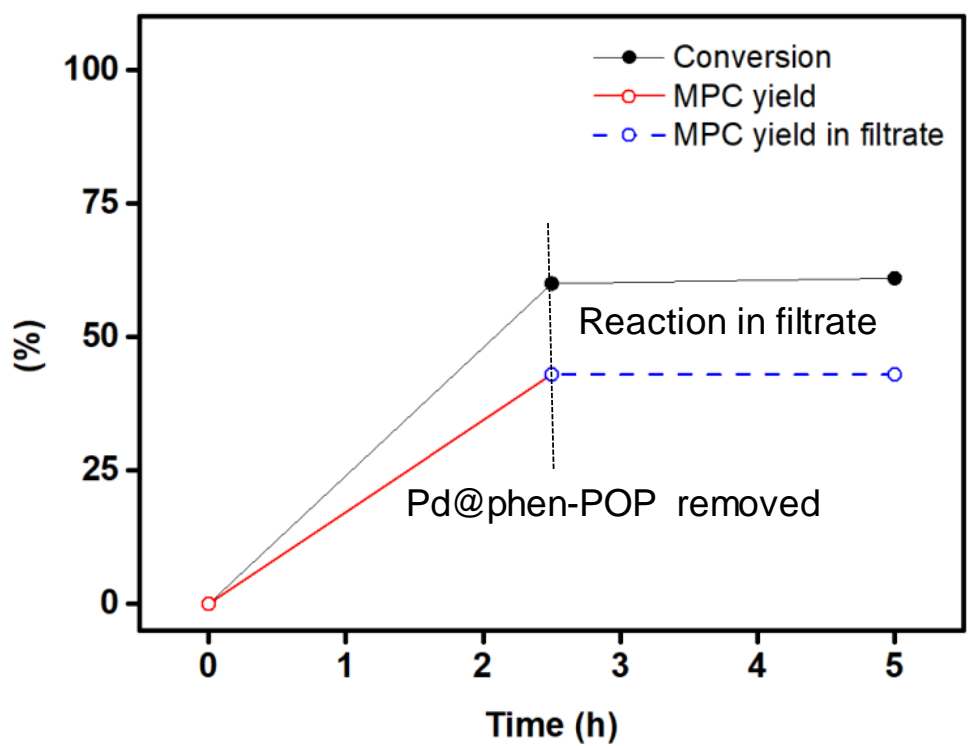

Reaction Conditions: The catalytic reaction was performed at $170{ }^{\circ} \mathrm{C}$ under 60 bar $\mathrm{CO}$ with an $\mathrm{S} / \mathrm{C}$ ratio of 300 . Yields of the reaction were obtained by the gas chromatography (GC) analysis. Solid black line represents the conversion of nitrobenzene (NB). Solid red line shows the MPC yield generated from the reaction with $2.5 \mathrm{~h}$ in original reaction mixture. Dotted blue line shows the MPC yield in the filtrate after removal of 3. After additional $2.5 \mathrm{~h}$ without $\mathbf{3}$, no further increment was detected.

Figure S8. The $\mathrm{Pd} 3 d$ core region of the Pd atom in the XPS spectrum of 3 after pre-treatment with $\mathrm{CO}$ at $170{ }^{\circ} \mathrm{C}$ for $24 \mathrm{~h}$ showing the generation of $\operatorname{Pd}(0)$ particles.

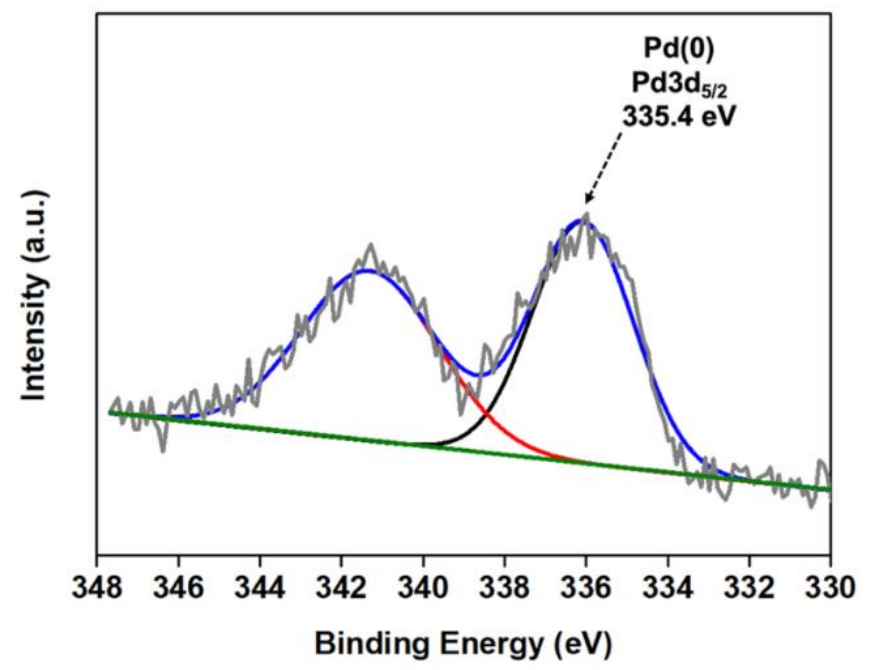


Figure S9. Transmission electron microscopy (TEM) image of the spent catalyst.

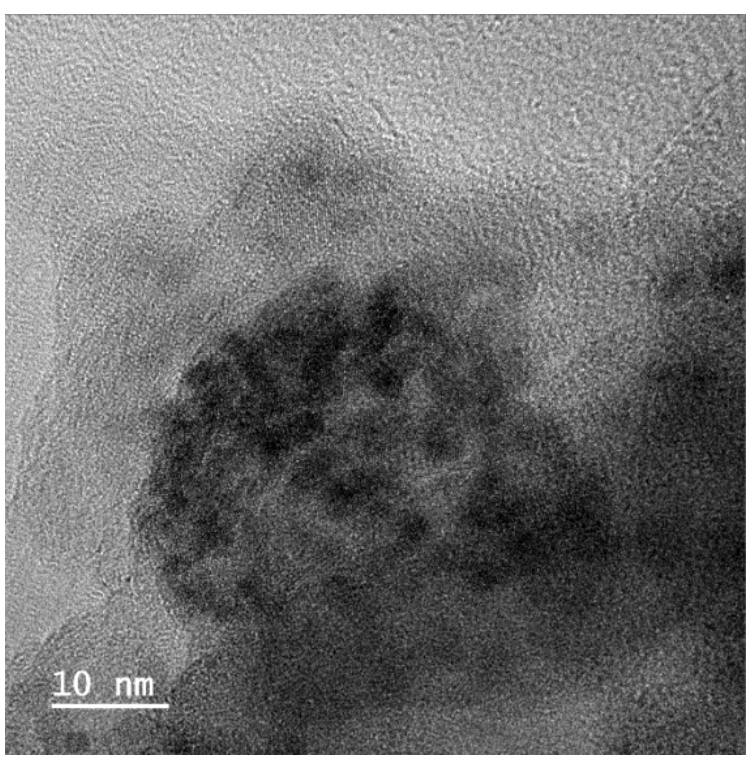

Figure S10. PXRD pattern of spent catalyst showing the formation of Pd nanoparticle

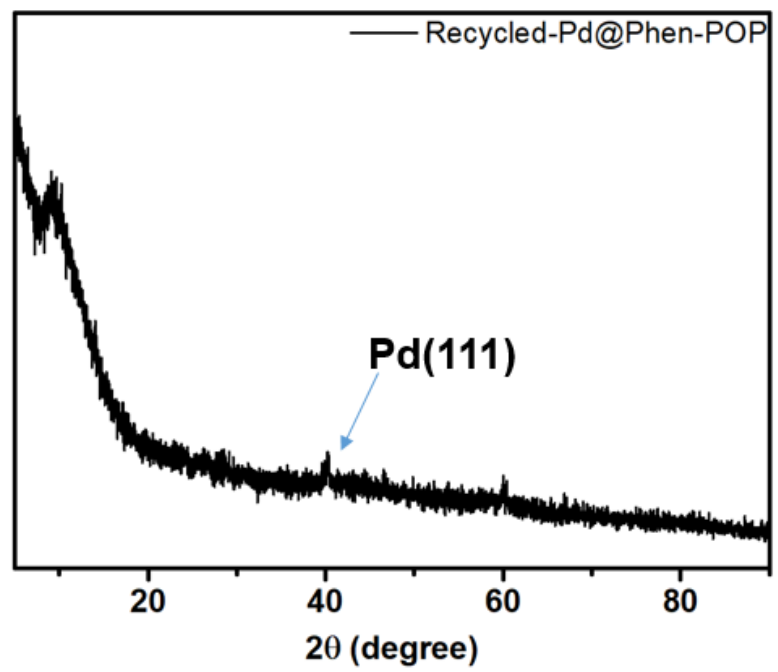


Figure S11. A GC-trace for the reductive carbonylation of NB for Entry 1, Table 1. The retention time for MPC is $10.0 \mathrm{~min}$. The amount of MPC was determined using a calibration curve with the linear relationship: $y=62.494 x-0.0735$ (x: concentration $(\mathrm{M})$ of MPC, and $y$ : ratio of area between MPC and internal standard $=0.16$ ). Amount of MPC $=0.0038 \mathrm{M}$ in a total volume of $8.1 \mathrm{~mL}$ corresponds to $0.03 \mathrm{mmol}$. TON $=\mathrm{mol}$ of $\mathrm{MPC} / 1.88 \mu \mathrm{mol}$ of $\mathrm{Pd})=16$.

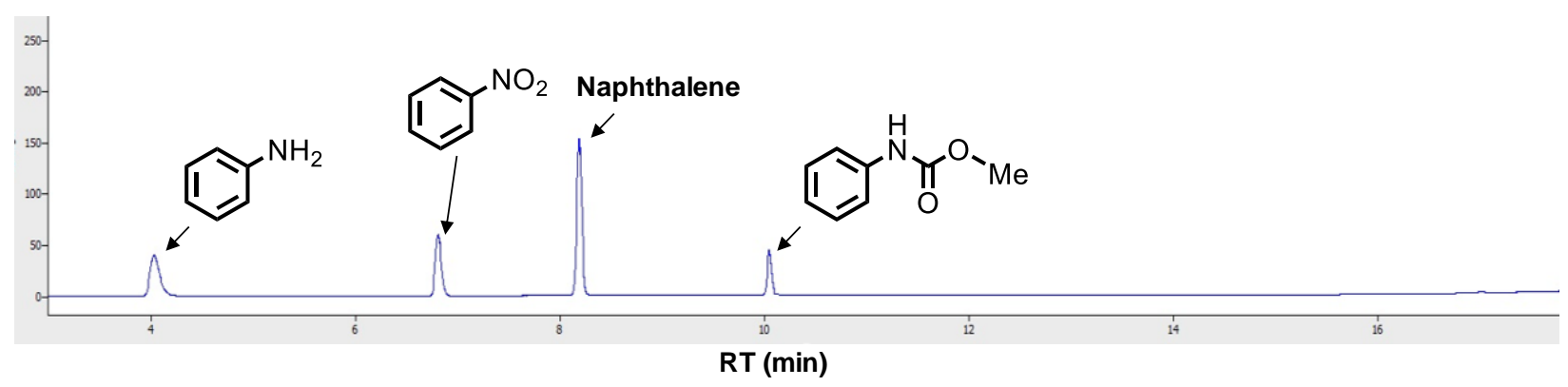

Figure S12. A GC-trace for the reductive carbonylation of NB for Entry 6, Table 1. The retention time for MPC is $10.0 \mathrm{~min}$. The amount of MPC was determined using a calibration curve with the linear relationship: $y=62.494 x-0.0735$ (x: concentration $(\mathrm{M})$ of MPC, and $y$ : ratio of area between MPC and internal standard $=1.35$ ). Amount of MPC $=0.023 \mathrm{M}$ in a total volume of $7.5 \mathrm{~mL}$ corresponds to $0.175 \mathrm{mmol}$. TON $=$ mol of MPC $/ 1.88 \mu \mathrm{mol}$ of Pd $)=92$.

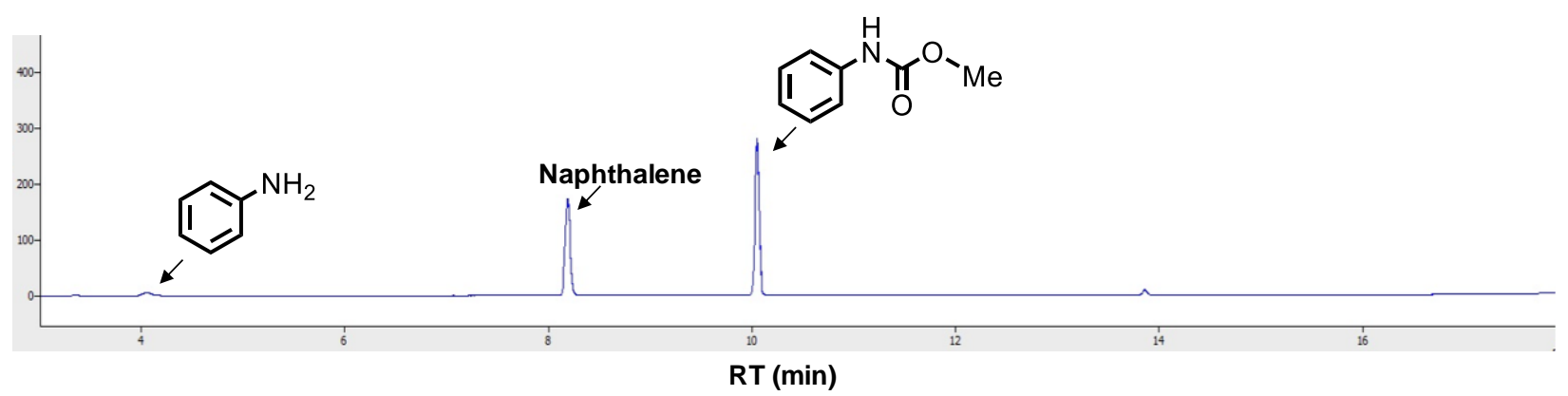


Figure S13. A GC-trace for the reductive carbonylation of NB for Entry 8, Table 1. The retention time for MPC is $10.0 \mathrm{~min}$. The amount of MPC was determined using a calibration curve with the linear relationship: $y=62.494 x-0.0735$ (x: concentration $(\mathrm{M})$ of MPC, and $y$ : ratio of area between MPC and internal standard $=5.97$ ). Amount of MPC $=0.097 \mathrm{M}$ in a total volume of $10.3 \mathrm{~mL}$ corresponds to $1.0 \mathrm{mmol}$. TON $=$ mol of MPC $/ 1.88 \mu \mathrm{mol}$ of $\mathrm{Pd})=533$.

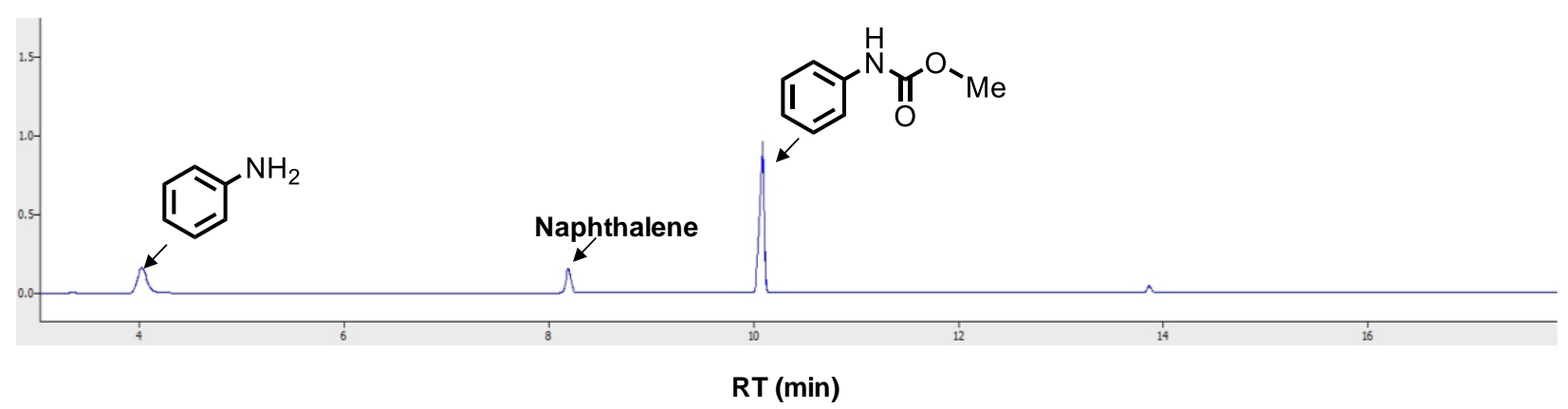

Figure S14. A GC-trace for the reductive carbonylation of NB for Entry 11, Table 1. The retention time for MPC is $10.0 \mathrm{~min}$. The amount of MPC was determined using a calibration curve with the linear relationship: $y=62.494 x-0.0735$ (x: concentration $(M)$ of MPC, and $y$ : ratio of area between MPC and internal standard $=1.99$ ). Amount of $\mathrm{MPC}=0.033 \mathrm{M}$ in a total volume of $5.3 \mathrm{~mL}$ corresponds to $0.176 \mathrm{mmol}$. TON $=$ mol of MPC $/ 1.88 \mu$ mol of Pd $)=93$.

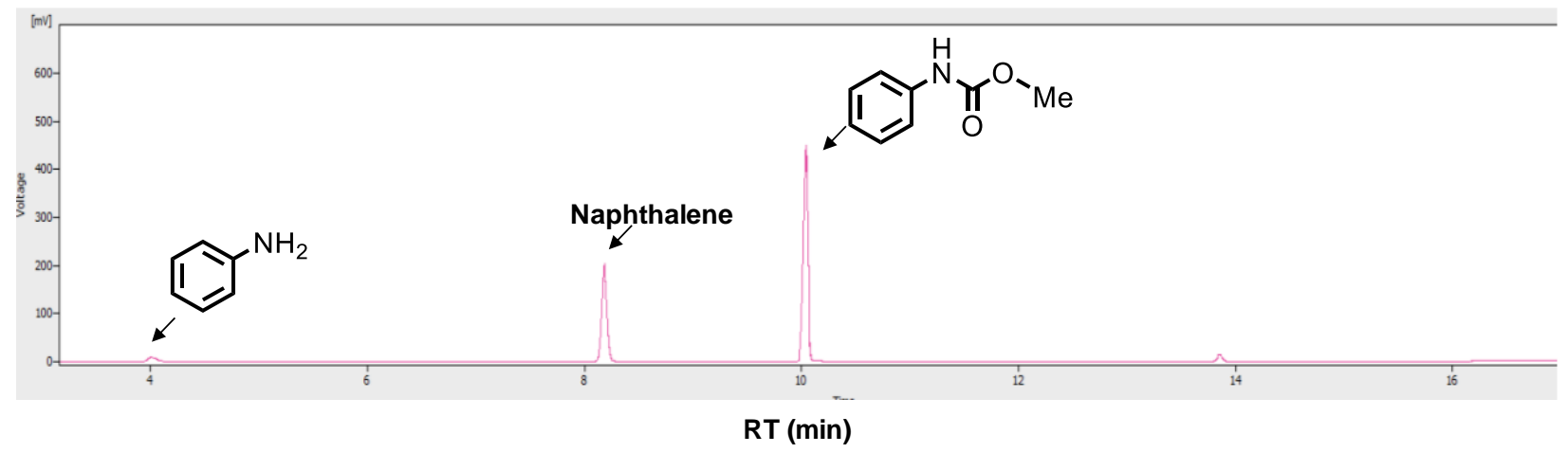


Figure S15. A GC-calibration curve for the quantification of MPC. Blue X-mark $=A_{\text {sub }} / A_{\text {int.Std }}$ for Entry 1, Table 1; Green X-mark = Asub $/ A_{\text {int.Std }}$ for Entry 6, Table 1; Red X-mark $=A_{\text {sub }} / A_{\text {int.Std }}$ for Entry 8, Table 1.

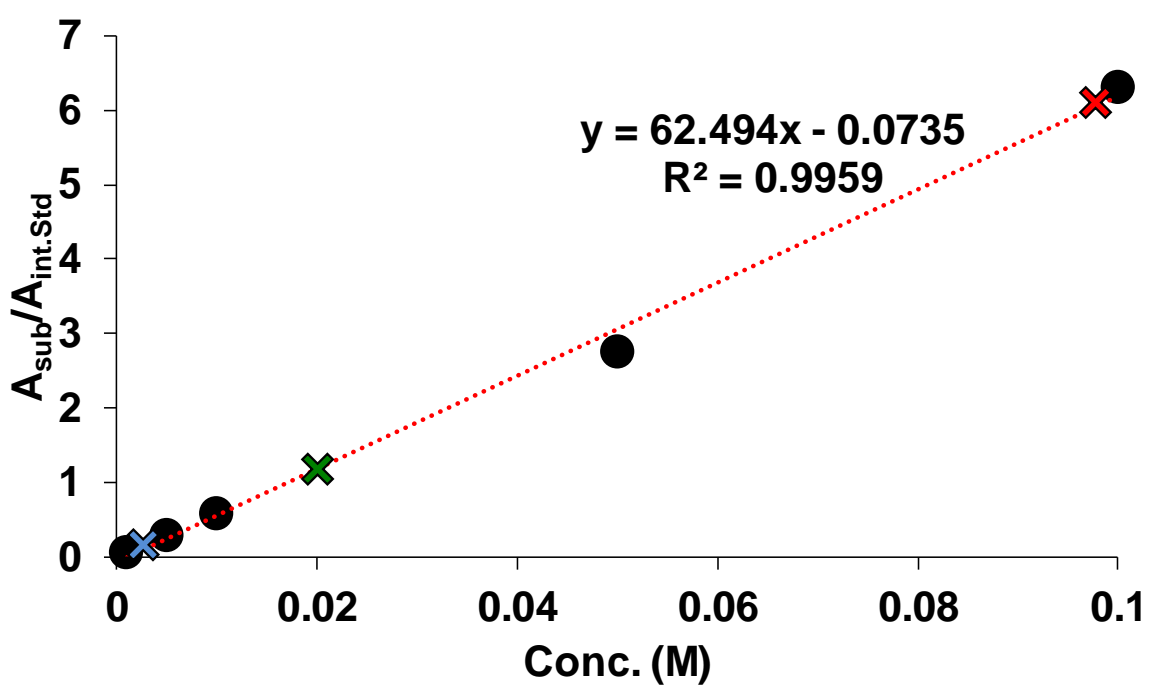




\section{GC traces for the hot filtration test:}

Figure S16. A GC-trace for the original reaction mixture after $2.5 \mathrm{~h}$. The retention time for MPC is $10.0 \mathrm{~min}$. The amount of MPC was determined using a calibration curve with the linear relationship between the concentration and area for both MPC and an internal standard naphthalene: $y=62.494 \mathrm{x}-0.0735$ (x: concentration $(\mathrm{M})$ of MPC, and $\mathrm{y}$ : ratio of area between $\mathrm{MPC}$ and internal standard $=1.59$ ). Amount of $\mathrm{MPC}=0.027 \mathrm{M}$ in a total volume of $9.3 \mathrm{~mL}$ corresponds to $0.25 \mathrm{mmol}$.

Amount of MPC formed $=0.25 \mathrm{mmol}(44 \%)$

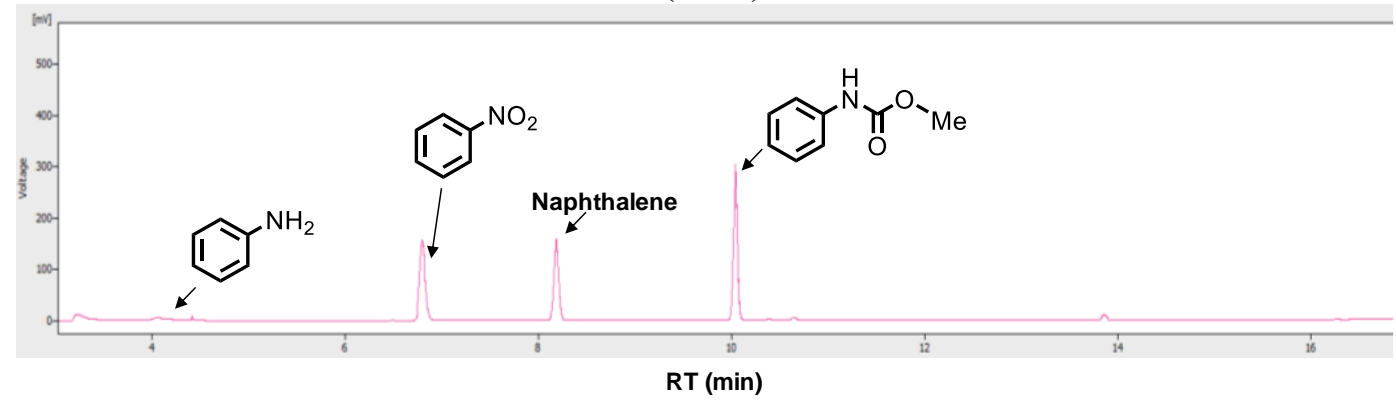

Figure S17. A GC-trace for the reaction in filtrate after removal of 3 . The retention time for MPC is $10.0 \mathrm{~min}$. The amount of MPC was determined using a calibration curve: $\mathrm{y}=62.494 \mathrm{x}-$ 0.0735 (x: concentration $(\mathrm{M})$ of MPC, and y: ratio of area between MPC and internal standard = 1.4). Amount of $\mathrm{MPC}=0.024 \mathrm{M}$ in a total volume of $7.7 \mathrm{~mL}$ corresponds to $0.184 \mathrm{mmol}$. (Increment in the initial volume of $6.8 \mathrm{~mL}$ is due to the additional $\mathrm{MeOH}$ solvent used to transfer the contents from the reactor). $5.4 \mathrm{~g}$ of filtrate from the original reaction mixture containing $0.184 \mathrm{mmol}$ of MPC was used for the hot filtration test reaction with the filtrate. Therefore, MPC yield in $5.4 \mathrm{~g}$ of the filtrate in the reaction after removal of $3=0.184 \mathrm{mmol}$.

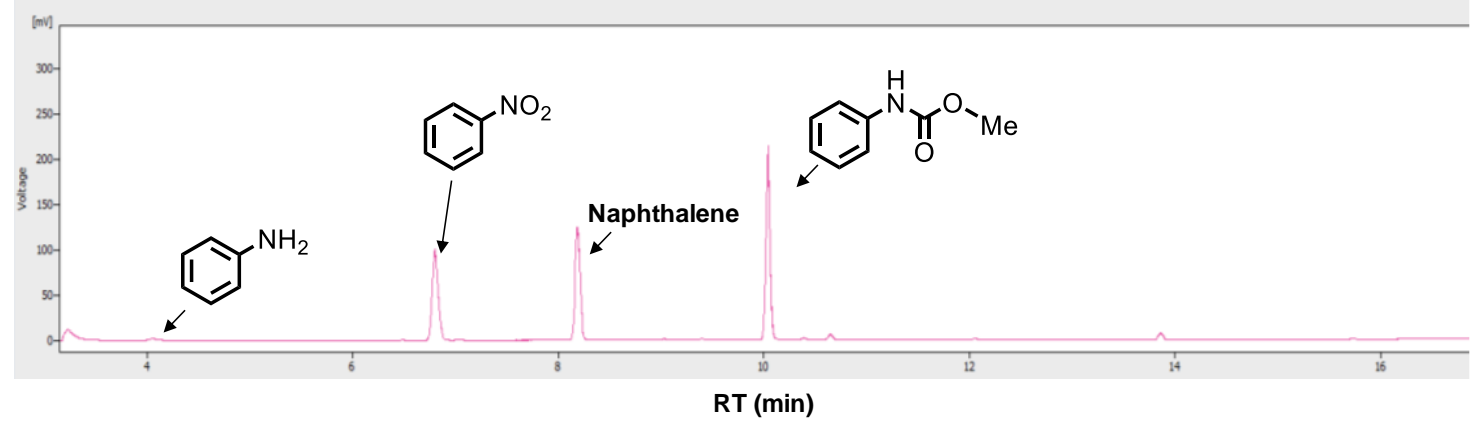


Figure S18. A GC-trace for the reaction of $\mathrm{NB}$ using in situ-generated $\operatorname{Pd}(0)$ nanoparticles by pre-treating catalyst 3 under 60 bar $\mathrm{CO}$ at $170{ }^{\circ} \mathrm{C}$ for $24 \mathrm{~h}$. No MPC formation detected at the RT $10.0 \mathrm{~min}$.

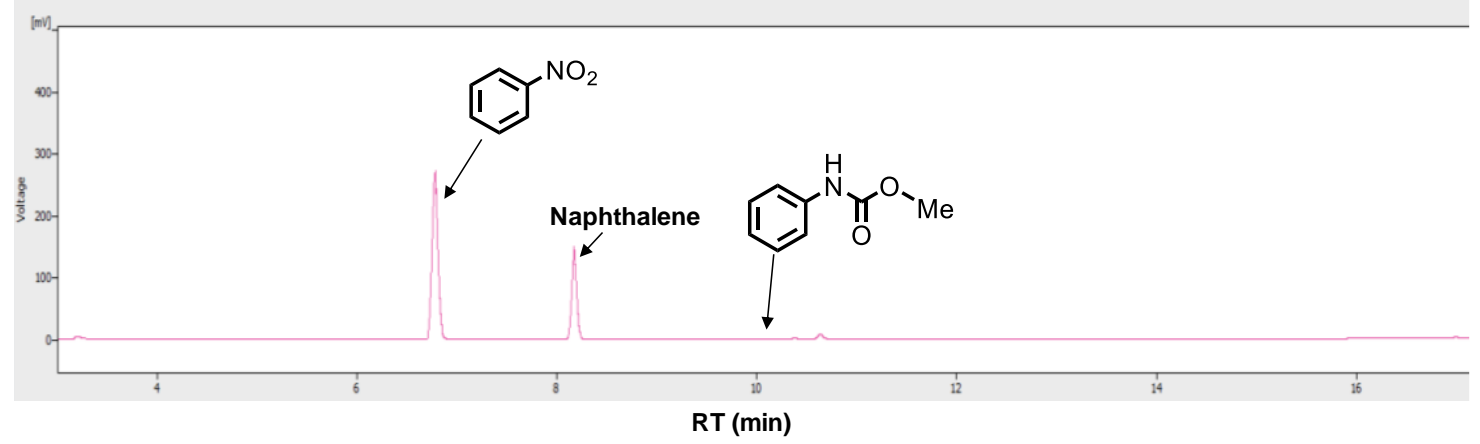

Figure S19. A GC-trace for the blank reaction by using support 2. No MPC formation detected at the RT $10.0 \mathrm{~min}$. Reaction condition: $10 \mathrm{mg}$ support, $0.188 \mathrm{mmol}$ of $\mathrm{NB}, 60$ bar $\mathrm{CO}, 170{ }^{\circ} \mathrm{C}$ for $3 \mathrm{~h}$.

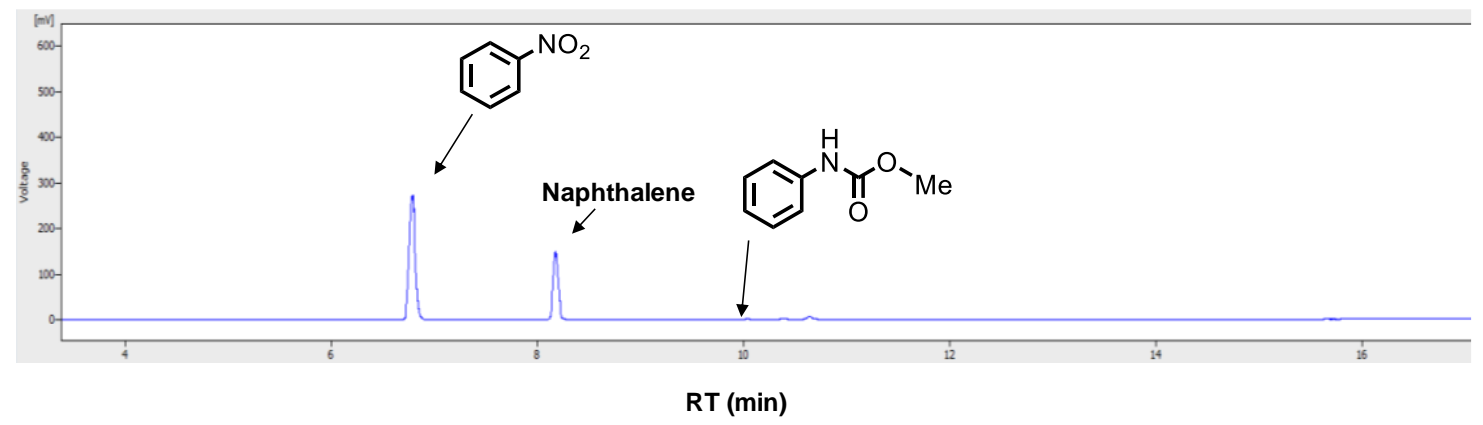




\section{${ }^{1} \mathrm{H}-\mathrm{NMR}$ spectra}

Figure S20. (a) ${ }^{1} \mathrm{H}$ NMR spectrum of $\mathrm{NB}$ in $\mathrm{CD}_{2} \mathrm{Cl}_{2}$ in comparison with (b) ${ }^{1} \mathrm{H}$ NMR spectrum of the reaction mixture from Entry 1, Table 2 in $\mathrm{CD}_{2} \mathrm{Cl}_{2}$ showing the formation of MPC (blue solid circle: NB, red solid circle: MPC, black star: internal standard, magenta star: Benzoic acid). A portion of $2.594 \mathrm{~g}$ obtained from a total of $5.408 \mathrm{~g}$ of crude solution was concentrated under vacuum. To this was added $0.071 \mathrm{mmol}$ of mesitylene and the mixture was dissolved in $\mathrm{CD}_{2} \mathrm{Cl}_{2}$. The NMR ratio for MPC to mesitylene $=1.25: 1$ corresponds to $0.089 \mathrm{mmol}$ of MPC in $2.594 \mathrm{~g}$. Total amount of MPC in a $5.408 \mathrm{~g}$ solution $=0.185 \mathrm{mmol}$. TON $(\mathrm{mol}$ of MPC $/ 1.88 \mu \mathrm{mol}$ of Pd) $=98$. (c) ${ }^{1} \mathrm{H}$ NMR spectrum of MPC after purification by column chromatography. ${ }^{1} \mathrm{H}$ NMR (400 $\mathrm{MHz}, \mathrm{CD}_{2} \mathrm{Cl}_{2}$ ): $\delta 7.39$ (d, $\left.J=8.0 \mathrm{~Hz}, 2 \mathrm{H}\right), 7.30(\mathrm{t}, J=7.6 \mathrm{~Hz}, 2 \mathrm{H}), 7.06(\mathrm{td}, J=7.4,1.0 \mathrm{~Hz}, 1 \mathrm{H})$, $6.79(\mathrm{~s}, 1 \mathrm{H}), 3.75(\mathrm{~s}, 3 \mathrm{H})$.
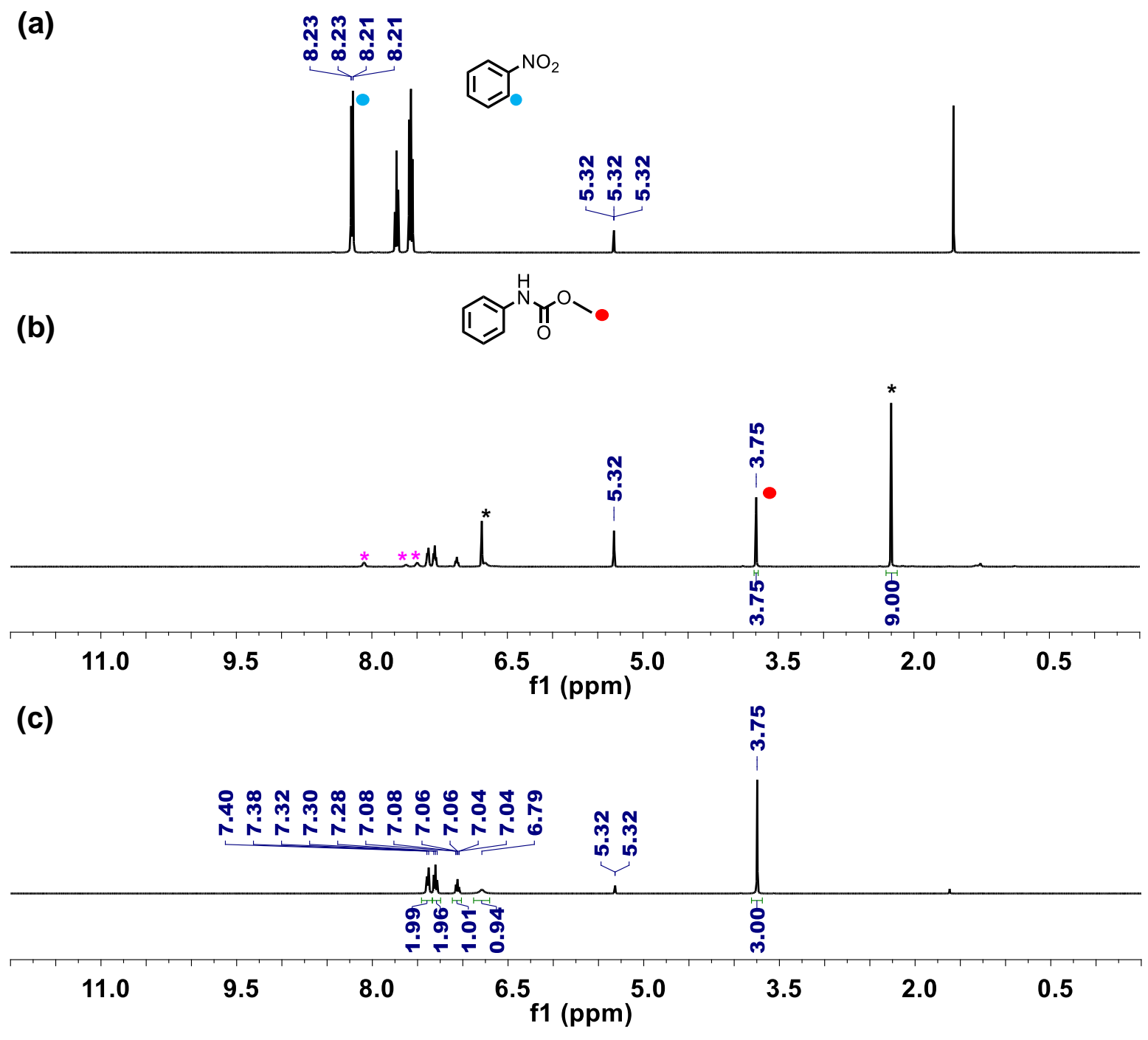
Figure S21. (a) ${ }^{1} \mathrm{H}$ NMR spectrum of 4-nitrotoluene in $\mathrm{CD}_{2} \mathrm{Cl}_{2}$ in comparison with (b) ${ }^{1} \mathrm{H}$ NMR spectrum of the reaction mixture from Entry 2, Table 2 in $\mathrm{CD}_{2} \mathrm{Cl}_{2}$ showing the formation of Methyl-N-p-tolylcarbamate (blue solid circle: 4-nitrotoluene, red solid circle: Methyl-N-ptolylcarbamate, black star: internal standard, magenta star: Benzoic acid). A portion of $1.201 \mathrm{~g}$ obtained from a total of $6.317 \mathrm{~g}$ of crude solution was concentrated under vacuum. To this was added $0.071 \mathrm{mmol}$ of mesitylene and the mixture was dissolved in $\mathrm{CD}_{2} \mathrm{Cl}_{2}$. The NMR ratio for Methyl-N-p-tolylcarbamate to mesitylene $=0.5: 1$ corresponds to $0.0355 \mathrm{mmol}$ of Methyl-N-ptolylcarbamate in $1.201 \mathrm{~g}$. Total amount of Methyl-N-p-tolylcarbamate in a $6.317 \mathrm{~g}$ solution $=$ $0.187 \mathrm{mmol}$. TON (mol of Methyl-N-p-tolylcarbamate/1.88 $\mu \mathrm{mol}$ of Pd) $=99$.

(a)

a)

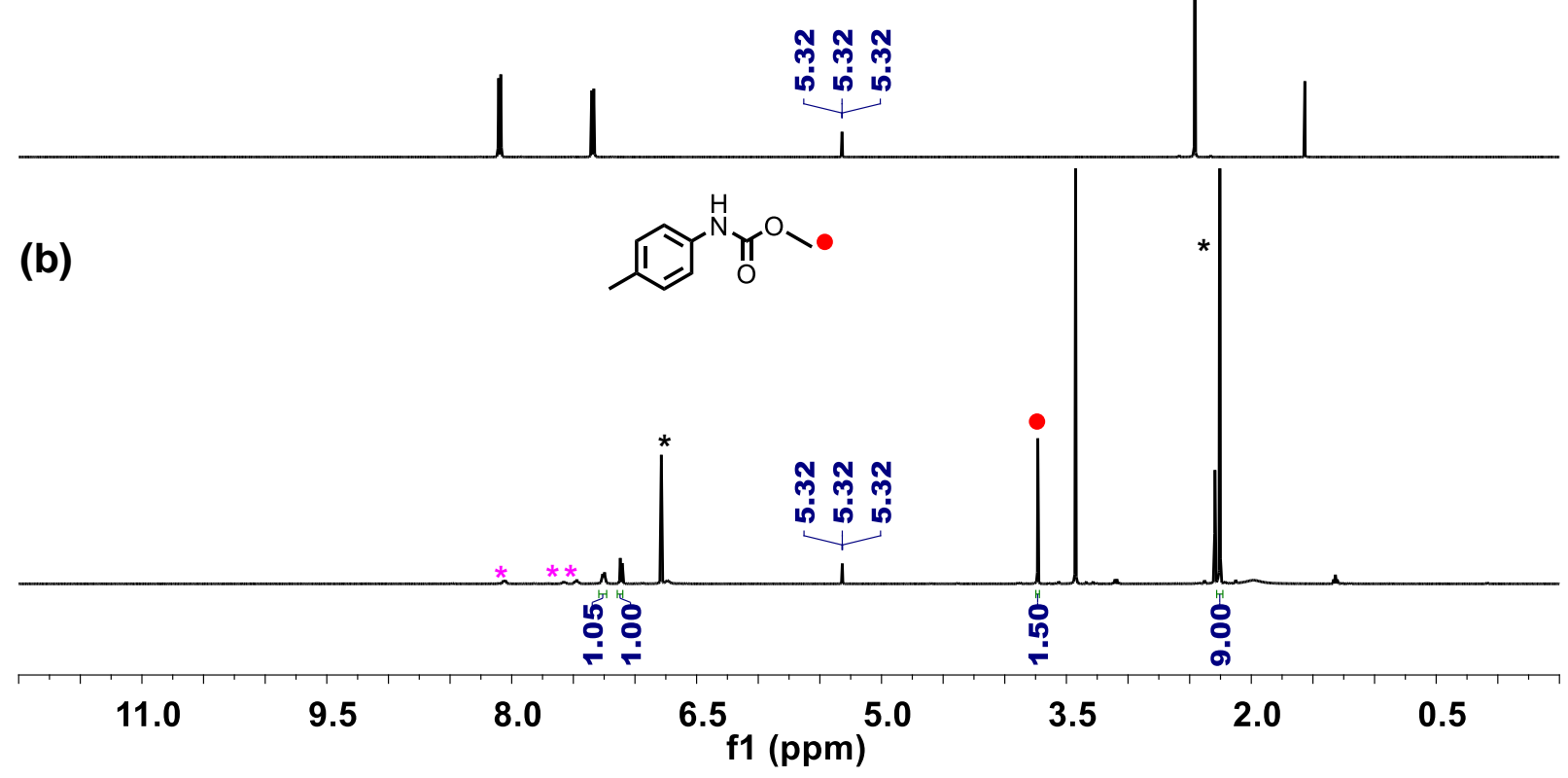


Figure S22. (a) ${ }^{1} \mathrm{H}$ NMR spectrum of 4-nitroanisole in $\mathrm{CD}_{2} \mathrm{Cl}_{2}$ in comparison with (b) ${ }^{1} \mathrm{H}$ NMR spectrum of the reaction mixture from Entry 3, Table 2 in $\mathrm{CD}_{2} \mathrm{Cl}_{2}$ showing the formation of methyl-N-(4-methoxyphenyl)carbamate (blue solid circle: 4-nitroanisole, red solid circle: methyl-N-(4-methoxyphenyl)carbamate, black star: internal standard, magenta star: Benzoic acid). A portion of $1.524 \mathrm{~g}$ obtained from a total of $7.631 \mathrm{~g}$ of crude solution was concentrated under vacuum. To this was added $0.071 \mathrm{mmol}$ of mesitylene and the mixture was dissolved in $\mathrm{CD}_{2} \mathrm{Cl}_{2}$. The NMR ratio for methyl-N-(4-methoxyphenyl)carbamate to mesitylene $=0.3: 1$ corresponds to $0.021 \mathrm{mmol}$ of methyl-N-(4-methoxyphenyl)carbamate in $1.524 \mathrm{~g}$. Total amount of methyl-N-(4-methoxyphenyl)carbamate in a $7.631 \mathrm{~g}$ solution $=0.105 \mathrm{mmol}$. TON $(\mathrm{mol}$ of methyl-N-(4-methoxyphenyl)carbamate/1.88 $\mu$ mol of Pd) $=56$.

(a)

a)

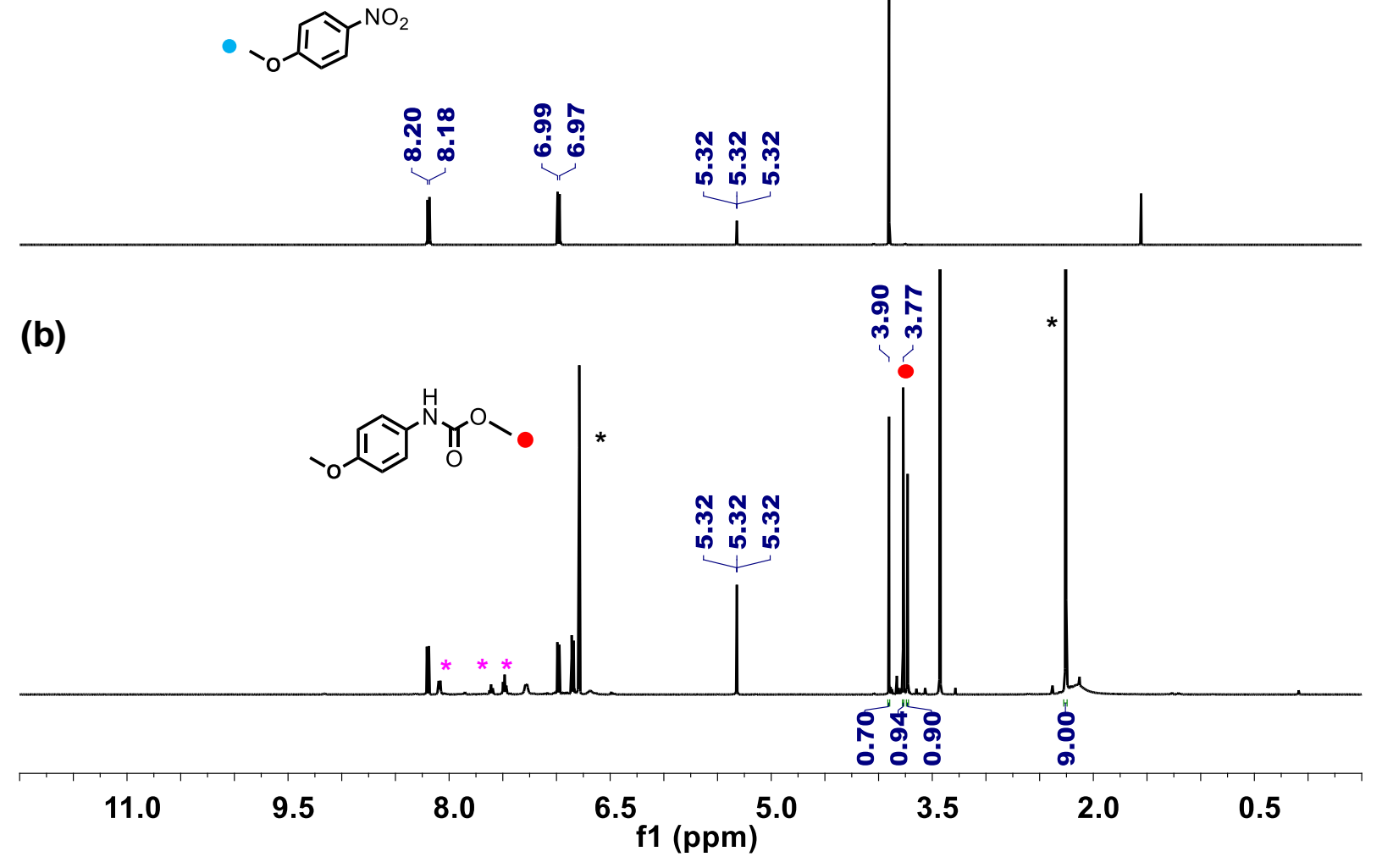


Figure S23. (a) ${ }^{1} \mathrm{H}$ NMR spectrum of 3-nitroanisole in $\mathrm{CD}_{2} \mathrm{Cl}_{2}$ in comparison with (b) ${ }^{1} \mathrm{H}$ NMR spectrum of the reaction mixture from Entry 4, Table 2 in $\mathrm{CD}_{2} \mathrm{Cl}_{2}$ showing the formation of methyl-N-(3-methoxyphenyl)carbamate (blue solid circle: 3-nitroanisole, red solid circle: methyl-N-(3-methoxyphenyl)carbamate, black star: internal standard, magenta star: Benzoic acid). A portion of $1.750 \mathrm{~g}$ obtained from a total of $5.110 \mathrm{~g}$ of crude solution was concentrated under vacuum. To this was added $0.071 \mathrm{mmol}$ of mesitylene and the mixture was dissolved in $\mathrm{CD}_{2} \mathrm{Cl}_{2}$. The NMR ratio for methyl-N-(3-methoxyphenyl)carbamate to mesitylene $=0.9: 1$ corresponds to $0.064 \mathrm{mmol}$ of Methyl-N-3-methoxyphenylcarbamate in $1.75 \mathrm{~g}$. Total amount of methyl-N-(3-methoxyphenyl)carbamate in a $5.110 \mathrm{~g}$ solution $=0.187 \mathrm{mmol}$. TON (mol of methyl-N-(3-methoxyphenyl)carbamate/1.88 $\mu$ mol of Pd) $=99$.

(a)

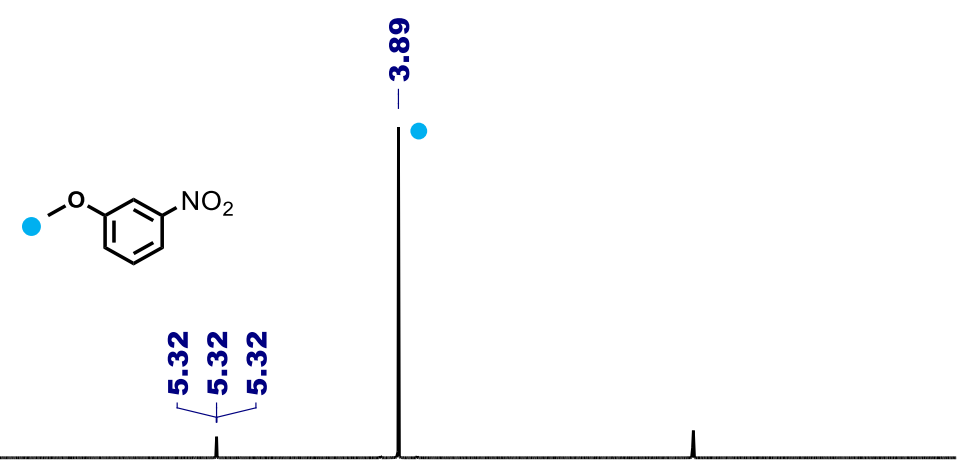

(b)

ald

1
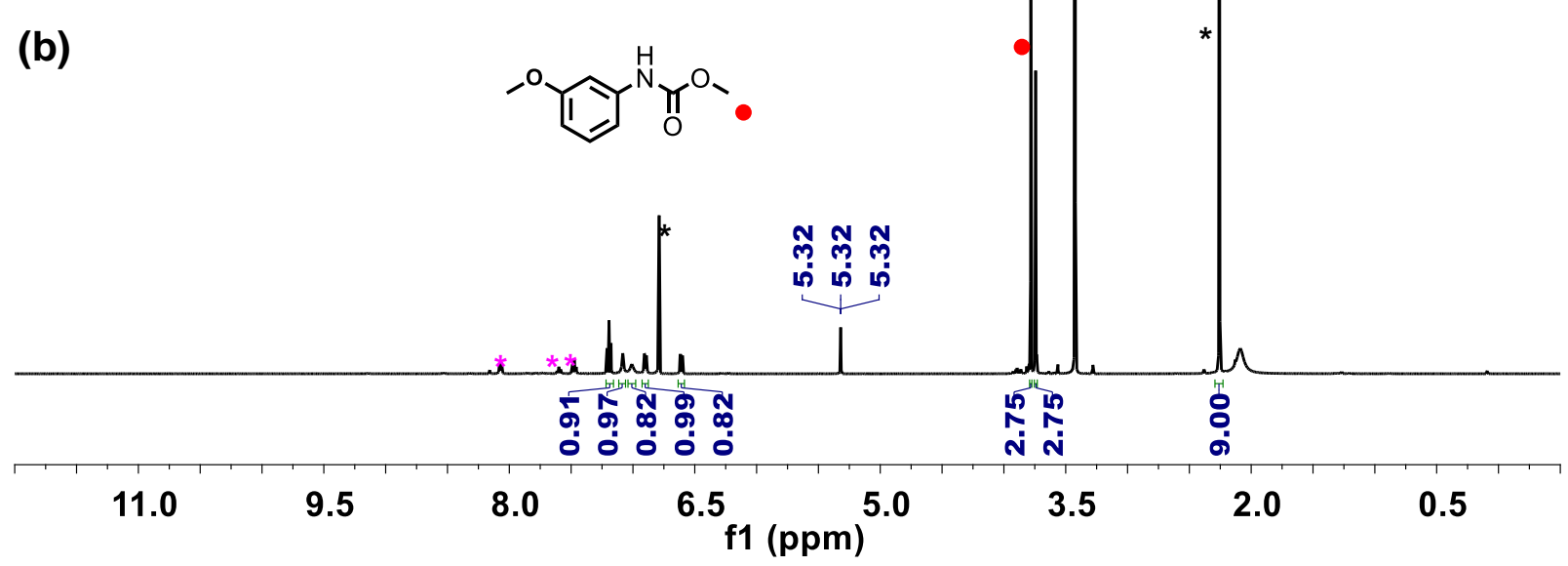
Figure S24. (a) ${ }^{1} \mathrm{H}$ NMR spectrum of 4-acedtyl nitrobenzene in $\mathrm{CD}_{2} \mathrm{Cl}_{2}$ in comparison with (b) ${ }^{1} \mathrm{H}$ NMR spectrum of the reaction mixture from Entry 5, Table 2 in $\mathrm{CD}_{2} \mathrm{Cl}_{2}$ showing the formation of methyl-N-(4-acetylphenyl)carbamate (blue solid circle: 4-acetyl nitrobenzene, red solid circle: methyl-N-(4-acetylphenyl)carbamate, black star: internal standard, magenta star: Benzoic acid). A portion of $1.181 \mathrm{~g}$ obtained from a total of $6.243 \mathrm{~g}$ of crude solution was concentrated under vacuum. To this was added $0.071 \mathrm{mmol}$ of mesitylene and the mixture was dissolved in $\mathrm{CD}_{2} \mathrm{Cl}_{2}$. The NMR ratio for methyl-N-(4-acetylphenyl)carbamate to mesitylene = $0.4: 1$ corresponds to $0.028 \mathrm{mmol}$ of methyl-N-(4-acetylphenyl)carbamate in $1.181 \mathrm{~g}$. Total amount of methyl-N-(4-acetylphenyl)carbamate in a $6.243 \mathrm{~g}$ solution $=0.150 \mathrm{mmol}$. TON $(\mathrm{mol}$ of methyl-N-(4-acetylphenyl)carbamate $/ 1.88 \mu \mathrm{mol}$ of $\mathrm{Pd})=80$.

(a)
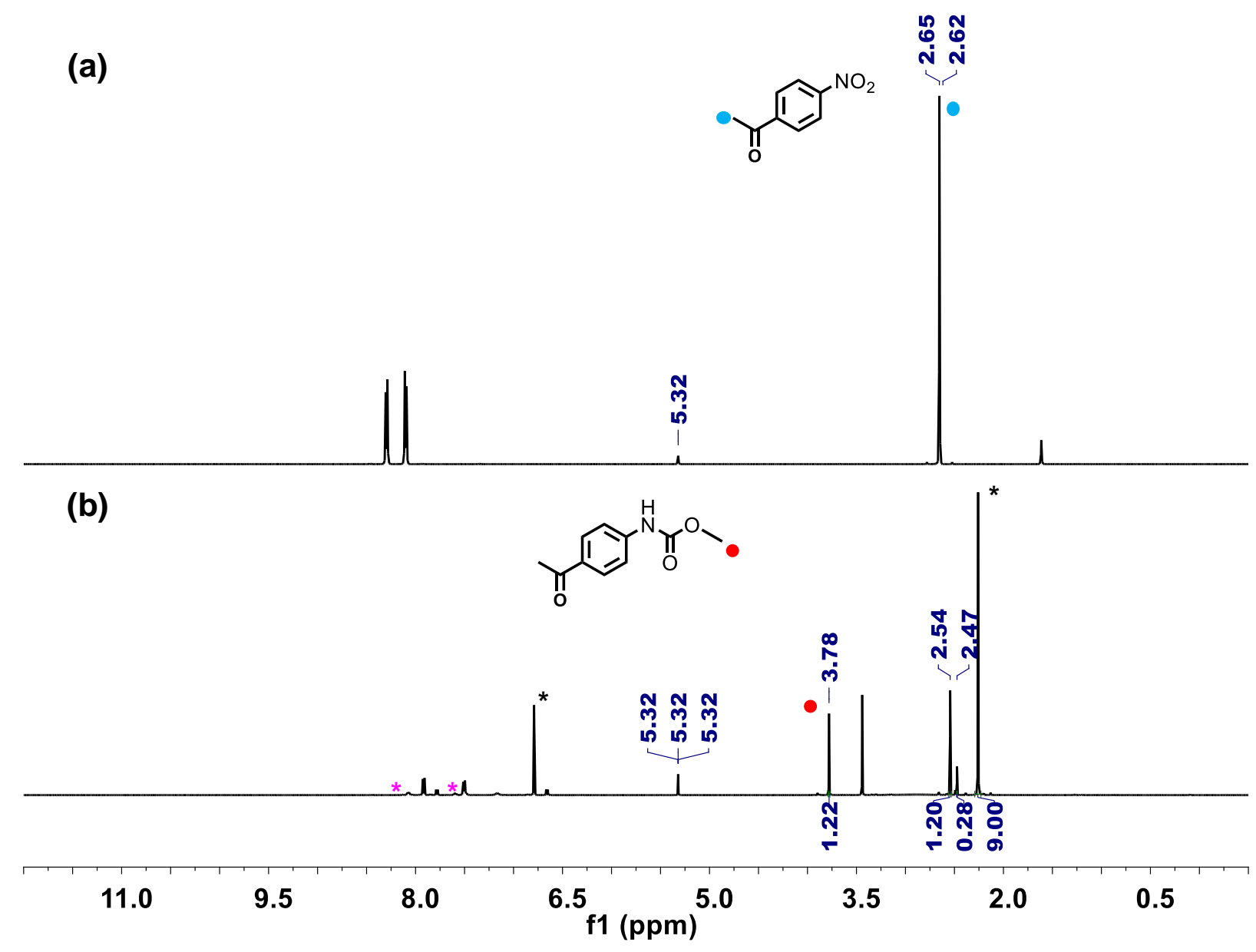
GC-MS data

Figure S25. GC-MS data for Entry 2, Table 2

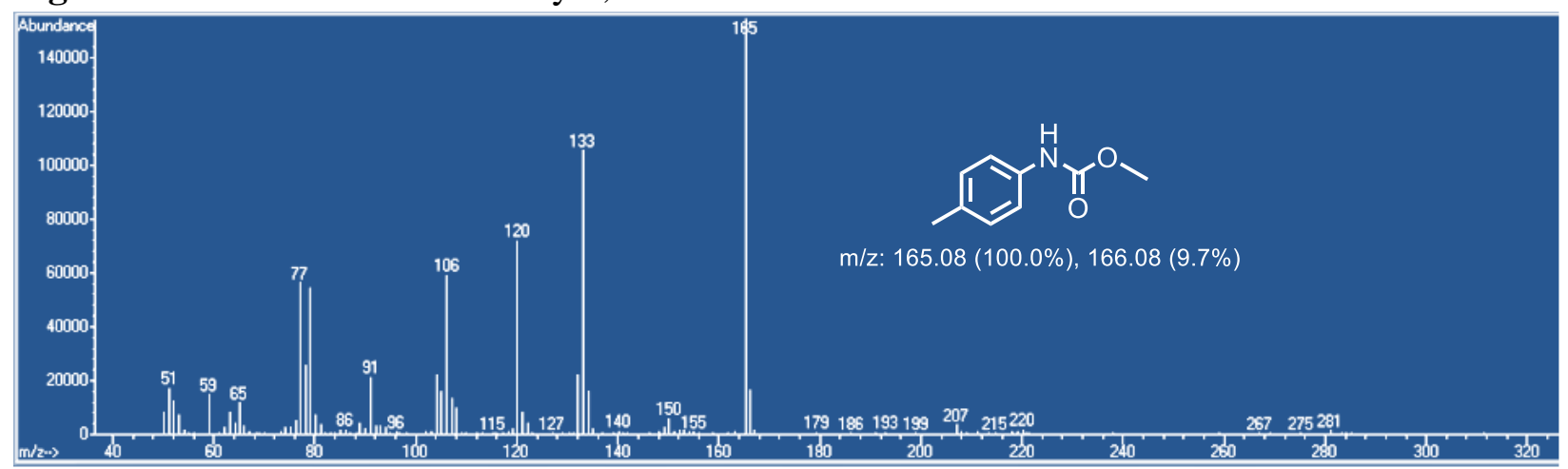

Figure S26. GC-MS data for Entry 3, Table 2

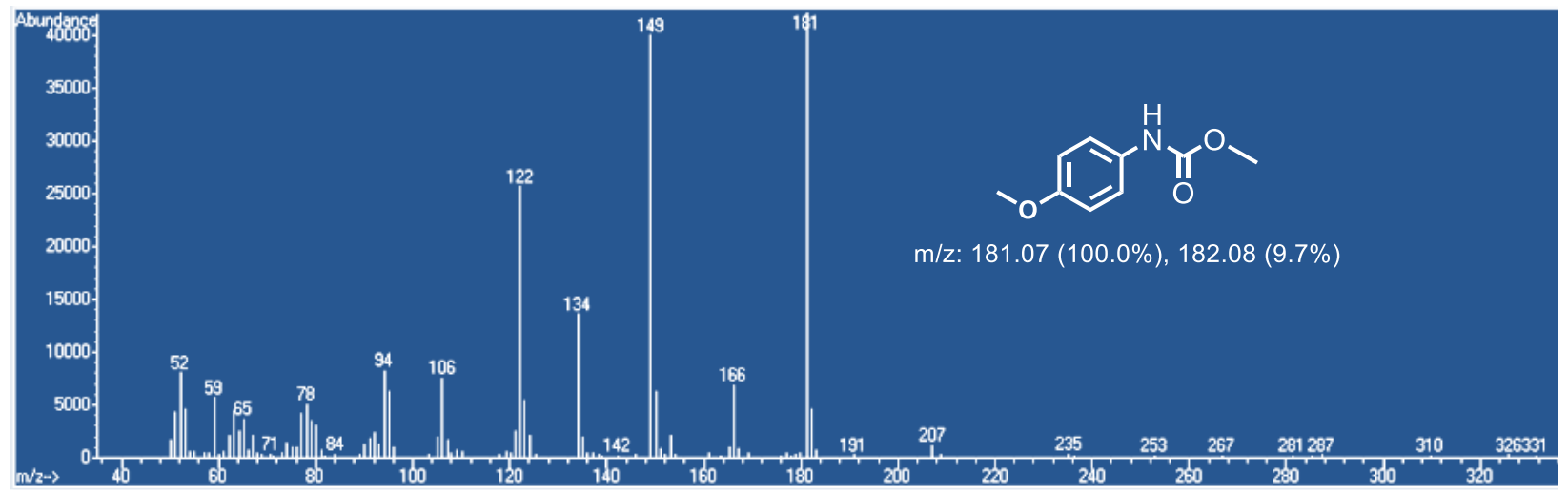

Figure S27. GC-MS data for Entry 4, Table 2

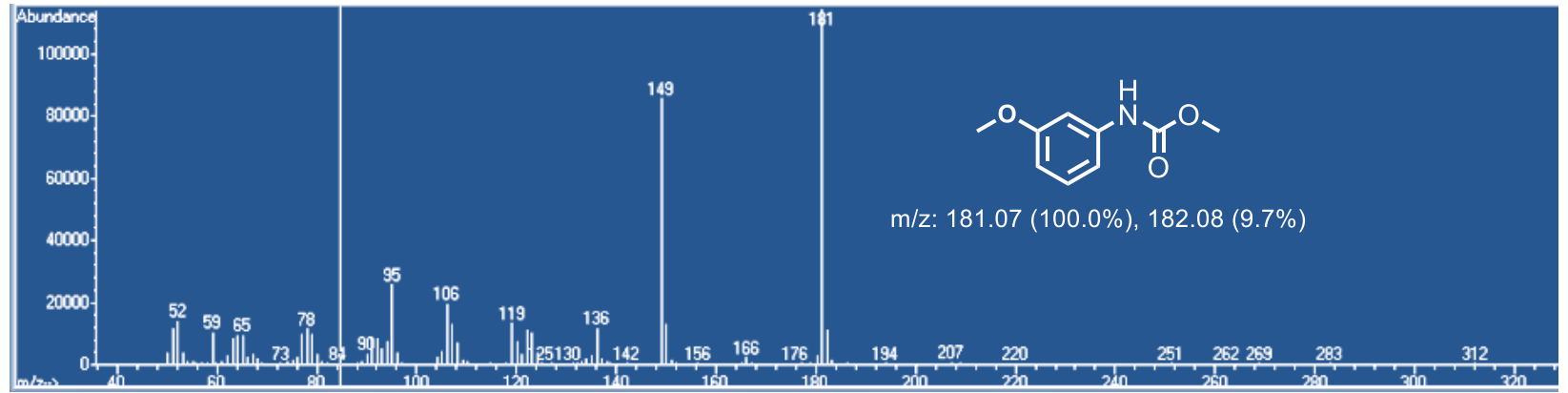


Figure S28. GC-MS data for Entry 5, Table 2

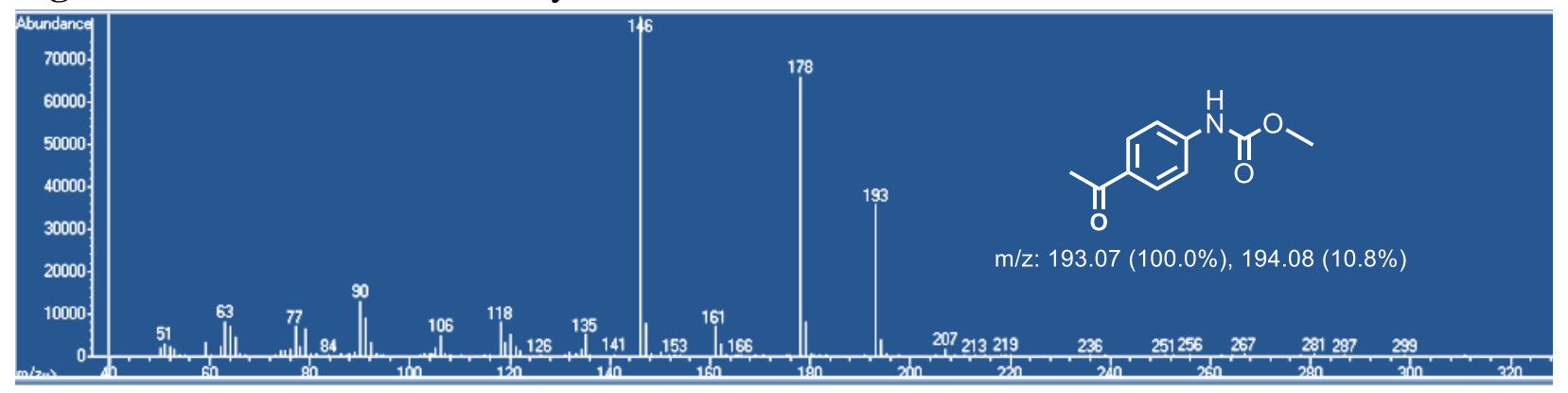

